\title{
En torno al currículo de Cultura Audiovisual en el Bachillerato: una reflexión crítica
}

\author{
On Audiovisual Culture Curriculum in the Baccalaureate: a Critical \\ Review
}

Luis Fernández Colorado

\section{Introducción}

Las enseñanzas de cultura audiovisual, reguladas de acuerdo al Real Decreto 1105/2014, de 26 de diciembre, por el que se establece el currículo básico de la Educación Secundaria y del Bachillerato, publicado en el Boletín Oficial del Estado del sábado 3 de enero de 2015, han estado sujetas desde su misma plasmación normativa a un intenso cuestionamiento en el ámbito docente.

Concebida con el "carácter propedéutico necesario y básico para su desarrollo en etapas posteriores, ya sea en estudios universitarios de comunicación audiovisual y publicidad, bellas artes (entre otros); como para los de formación profesional de imagen y sonido y enseñanzas artísticas ${ }^{\prime \prime}$, la materia se oferta como optativa en el bachillerato y los contenidos de su desarrollo curricular oscilan esencialmente entre lo tecnológico, lo industrial, lo fisiológico, lo analítico y lo creativo.

Pasado un tiempo prudencial desde su implantación, se antoja necesario establecer unas primeras revisiones críticas de los contenidos, criterios de evaluación y estándares de aprendizaje evaluables que presentan las dos asignaturas (Cultura Audiovisual I y Cultura Audiovisual II), con el objeto de efectuar una Ilamada a la reflexión colectiva sobre el devenir actual de estas enseñanzas y su innegable potencial futuro.

Un acercamiento al currículo

Los aspectos curriculares de las materias de bachillerato tienden a ser, casi por definición, extraordinariamente ambiciosos y abarcadores, al tiempo que difíciles de llevar a efecto en todas sus dimensiones dentro de los plazos marcados por el calendario académico y de las servidumbres cotidianas que vienen derivadas de la docencia en el aula a lo largo de todo un curso. Por otra parte, cuando determinadas materias llevan impartiéndose poco tiempo los

\footnotetext{
${ }^{1}$ Real Decreto 1105/2014, de 26 de diciembre, por el que se establece el currículo básico de la Educación Secundaria Obligatoria y del Bachillerato. Boletín Oficial del Estado, 3 de enero de 2015, p. 227.
} 


\section{taphiya $\mathbf{4 8}$}

ajustes necesarios que pueden requerir tardan en ser vistos y, sobre todo, corregidos, lo que inevitablemente lleva a la introducción paliativa de medidas transitorias y parciales que en ocasiones no siempre son las mejores, pero sí las que pueden llevarse a efecto con determinada racionalidad práctica en el corto plazo.

Viene lo anterior a colación del hecho de que cualquier análisis que desee formularse en torno la materia de Cultura Audiovisual está destinado a concluir que en ella se dan, al menos, ambos ingredientes: un evidente exceso de contenidos y un variopinto repertorio de decisiones adoptadas en cada momento para salir del paso.

De hecho, si algo cabe expresar de inicio es que resulta complicado definir el currículo básico de Cultura Audiovisual en pocas palabras, dado su ambicioso y presuntamente omnicomprensivo planteamiento global, que corre en paralelo a su afán por marcar de manera rígida ciertas directrices y límites dentro de tan amplio terreno de juego. Su tejido interno es, de hecho, impreciso, porque en realidad no es que pretenda abarcar mucho, aunque sea a costa de apretar poco, sino que más bien aspira a tener la apariencia genérica de estar cubriendo una enorme amplitud de cosas, pero sin dejar por ello de resistirse a dirigir de manera focalizada el trabajo cotidiano en las aulas hacia terrenos muy específicos y no siempre, ni necesariamente, los más atractivos para docentes y estudiantes o los más pegados al latido de la contemporaneidad. Sólo cabría felicitarse si eso contribuyera a facilitar la gestión docente en los centros de secundaria 0 a estimular ciertos intereses reales del alumnado que éste no tiene presentes de antemano, pero lo cierto es que tampoco parece orientado al logro de dichos objetivos. Los criterios que sustentan numerosas decisiones adoptadas en el currículo resultan confusos, hasta el punto de que tan gigantesco marco general, con varias decenas de contenidos repartidos en dos cursos, se antoja poco menos que inviable, escasamente flexible, añejo en sus planteamientos y en buena medida arbitrario.

Seguro que bastantes personas que conocen dicho currículo, así como por supuesto quienes lo esbozaron, no compartirán en absoluto estas expresiones críticas, ciertamente subjetivas, pero quizás la mejor manera de defenderlas sea utilizando, como puerta de entrada a nuestra reflexión crítica, un ejemplo concreto.

Empecemos, en ese sentido, con un simple acercamiento a la lectura de los contenidos, criterios de evaluación y estándares de aprendizaje evaluables del Bloque 1 (denominado como Integración de sonido e imagen en la creación de audiovisuales y new media), inserto en el currículo de la materia de segundo de bachillerato Cultura Audiovisual II.

Resulta ciertamente llamativo que pese a lo que enuncia la propia denominación de ese bloque, las referencias al ámbito del new media brillan casi por su ausencia. Los nada menos que trece contenidos del bloque, por otra parte bastante amplios y variados, abarcan aspectos generales del sonido (función expresiva, grabación y difusión, con particular referencia a tipos esenciales de microfonía o sistemas monofónicos, estereofónicos, dolby surround 5.1, mp3 y otros posibles²); cuestiones relacionadas con la integración del sonido en las producciones audiovisuales (pero no en los new media, puesto que de hecho se omite en la propia redacción del texto); el estudio de la banda sonora y de sus grandes creadores en la historia del cine; ciertos aspectos históricos vinculados al desarrollo del cinematógrafo (ni siquiera a la televisión 0 a la video-creación, con alusiones explíitas a la banda sonora en la historia del cine, la banda sonora en el cine español o los hitos históricos del proceso de transformación en los lenguajes y en los medios técnicos en el paso del cine mudo al sonoro ${ }^{3}$ ) e incluso, también el desarrollo histórico del género de la comedia en el cine, desde el slapstick en el cine mudo a las películas sonoras corales o dialogadas. Del new media apenas queda rastro más allá del enunciado general del bloque, por mucho que el término aparezca en el apartado octavo de los criterios de evaluación ${ }^{4}$ y en el punto 8.2.

\footnotetext{
${ }^{2}$ Ibid., p. 231.

${ }^{3}$ Ibid.

4 "Valorar la importancia de la función expresiva de la imagen, el sonido y la música en el proceso de creación de audiovisuales y de new media, analizando las funciones comunicativas y estéticas de los productos audiovisuales". Ibíd.
} 
de los estándares de aprendizaje evaluables ${ }^{5}$. Obviamente, todos los contenidos del bloque están claramente orientados hacia el sonido y el cine, por separado y juntos, ensartando además elementos tecnológicos (por ejemplo, tipos esenciales de microfonía), históricos (el paso del mudo al sonoro en el cine), expresivos (adecuación de la música y del sonido a las intenciones comunicativas), perceptivos (la relación perceptiva entre imagen y sonido) e incluso analíticos de un género (la evolución de ciertas tipologías de comedia cinematográfica). El término new media, por supuesto, reaparecerá en otros puntos del Real Decreto, salpimentado a veces su desarrollo normativo, pero justo donde expresamente figura en el enunciado del bloque es un contenido inexistente.

Especular con las motivaciones de esta aparente presencia (en el enunciado) y notoria ausencia (en contenidos) carece de sentido en estas páginas, por lo que de momento nos limitamos a constatar el hecho, si bien tampoco podemos resistirnos a señalar que acaso dichas motivaciones se encuentren subsumidas en el texto introductorio redactado para la propia norma legal, cuando se afirma lo siguiente:

EI siglo XXI presenta en su cabecera una revolución social en las comunicaciones: la era digital e internet. Estos dos elementos están suponiendo un cambio tal en los comportamientos sociales que cuesta aventurar hacia dónde caminan las nuevas generaciones nacidas dentro de este sistema de información e intercambio de datos. [...] Por primera vez en la historia, los creativos pueden alcanzar el reconocimiento de su obra sin pasar por el filtro de la industria audiovisual. Este apoyo inicial sivve como indicativo de calidad para una posterior integración de los nuevos creadores dentro de la industria audiovisual. Por otro lado, la facilidad de exposición del material ("subir a la red") no supone un aumento de la calidad de lo creado; muy al contrario, la realidad nos indica que la posibilidad ilimitada de generar fotos, vídeos, blogs y páginas web sin la ayuda del criterio razonado de la industria está inundando el mercado audiovisual de productos de calidad muy deficiente ${ }^{6}$.

En cualquier caso, y por seguir con el ejemplo que estamos utilizando para justificar nuestros comentarios en torno al planteamiento curricular, es interesante centrarse en los últimos apartados recogidos dentro de los contenidos de ese mismo Bloque I (recordemos, denominado como Integración de sonido e imagen en la creación de audiovisuales y new media), básicamente porque ahí aparecen creadores, con nombres y apellidos, como paradigmas de estudio. Así, por un lado, se plantea una curiosa diferenciación, dentro de los contenidos, entre el apartado de la banda sonora en la historia del cine, que se salda con un genérico "los grandes creadores" (así, sin nombres), en relación a la banda sonora en el cine español, donde expresamente se enuncia una larga nómina de creadores a estudiar que abarca desde Augusto Algueró hasta Adolfo Waitzman, pasando por Roque Baños, Bernardo Bonezzi, Carmelo Bernaola, Antón García Abril, Alberto Iglesias, José Nieto y Alfonso Santisteban, y que concluye, por si los citados fueran pocos, con un expresivo etcétera. Por otro, y de forma todavía más llamativa, esa integración de sonido e imagen en la creación de audiovisual se ciñe, de manera concreta, sólo al ámbito de la comedia, y para remate no deja espacio a posibles puntos de fuga: aquí no hay etcéteras ni adversativas, sino profusos 'en' y 'de': el slapstick en la obra de Mack Sennett', Max Linder y Charlie

\footnotetext{
5 "Identifica las funciones y necesidades de los sistemas técnicos empleados en la integración de imagen y sonido en un audiovisual o en new media". Ibid.

${ }^{6}$ Ibid., p. 226. Resulta cuando menos llamativa la asociación que se establece entre el proceso de cambio marcado por la era digital e internet únicamente con comportamientos sociales y con la dificultad para aventurar hacia dónde caminan las nuevas generaciones, en vez con nuevas posibles modalidades de expresión, formulaciones de lenguaje, estructuras narrativas o discursivas teóricas en torno a la creatividad en la cultura audiovisual contemporánea, etcétera. Entre otras cosas porque parece delatar una perspectiva moralizadora que acaso debería haberse obviado, al mismo tiempo que un cierto paternalismo en buena medida chocante cuando el currículo va dirigido a unos estudiantes de bachillerato, frisando la mayoría de edad, a los que, por supuesto, no deja de insistírseles, ya dentro de los contenidos de la asignatura que forma parte de la Evaluación para el Acceso a la Universidad, en "el uso responsable de la red" (Ibid., p. 232).

${ }^{7}$ En el texto original del Boletín Oficial del Estado aparece por error como Max Sennet.
} 


\section{taphiya $\mathbf{4 8}$}

Chaplin; la comedia visual en Buster Keaton y Harold Lloyd; la comedia dialogada y la obra cinematográfica de Woody Allen; la comedia coral y la obra cinematográfica de Luis García Berlanga. Estos son los nombres que deben ser estudiados de manera específica porque, entre otras cuestiones, son susceptibles de acabar siendo objeto de preguntas concretas en la prueba de evaluación para el acceso a la universidad. Es decir: este es el canon que se debe trabajar en las aulas, porque forma parte de los contenidos evaluables, de manera que aquí cabe formularse en voz alta, por lo tanto, numerosas preguntas y controvertidos interrogantes.

En primer lugar, ¿de verdad que la integración de sonido e imagen en la creación de audiovisuales está forzada a vertebrarse desde la comedia porque así lo exigen los contenidos? ¿No desde cualquier género, ni siquiera el musical? Suena, en verdad, chocante.

En segundo lugar, la lista de nombres, siete en total, acoge pintorescamente una mayoría de cineastas del período mudo, dentro de un contexto que, recordémoslo siempre, aborda la integración de sonido e imagen en la creación de audiovisuales. No parece que Mack Sennett o Buster Keaton, por ejemplo, fuesen muy duchos en ese ámbito, ni referencias internacionales muy señaladas en lo que se refiere a la integración sonido-imagen, así como tampoco un Max Linder cuyo suicidio se produjo cuando el cine se encontraba todavía en la etapa muda. El asunto sigue resultado chocante, cuando menos, pero lo es más si procedemos a expurgar una selecta nómina en la que aparecen cineastas sin duda maravillosos y muy destacados en su momento pero que, como ocurre con el ya citado Max Linder, en la actualidad son más pasto de auténticos especialistas que integrantes del común conocimiento masivo de cualquier aficionado: aquellos otros nombres que, dentro de ese mismo ámbito de la comedia con el que pretende jugar el bloque de contenidos, son creadores bastante más instalados en la memoria colectiva como Billy Wilder, los Hermanos Marx o Jerry Lewis (por no salirnos de Hollywood y del clasicismo).

Porque esa es otra cuestión: las referencias nominales dentro de los contenidos, como puede verse, no recogen la presencia de mujeres, ni de creadores ajenos al contexto occidental, ni de documentalistas, ni de directores vinculados a cualquier esfera de renovación creativa que pudiera haber surgido desde, digamos, los nuevos cines hasta la actualidad. Se mire por donde se mire, resulta cuando menos llamativo que la integración de sonido e imagen en la creación de audiovisuales omita nada menos que todo eso, de un plumazo, sin aparente motivación (más allá del gusto personal de quienes puedan haber elaborado el currículo).

Pero por si alguien piensa que todos esos aspectos pueden estar recogidos en otros bloques del currículo baste asomarse a la otra única relación nominal que aparece en los contenidos de ambas asignaturas, al margen de las hasta ahora enunciadas, para constatar básicamente lo mismo. Así, en Cultura Audiovisual I, en el Bloque 2 (La imagen fija y su capacidad expresiva), encontramos temas como la fotografía de moda, la fotografía en la publicidad, la fotografía como instrumento de denuncia social o la fotografía que busca construir una realidad paradójica. Los contenidos instan a trabajar sobre la obra gráfica de Mario Testino, Jaume de Laiguana, Eugenio Recuenco y Chema Madoz (aunque ciertamente luego en los estándares de evaluación aparecen otros nombres adicionales posibles como Martín Chambi, Irvin Penn, Cecil Beaton, Ansel Adams, Ernst Haas, Andy Warhol, Howard Schatz, Sebastiao Salgado, Kevin Carter, Manuel Pérez Barriopedro, Gervasio Sánchez y, en este caso sí, tres mujeres: Ouka Lele, Cristina García Rodero y Dorothea Lange). Como puede verse, básicamente es lo mismo: dentro del cuarteto de nombres que expresamente figuran en los contenidos (Testino, Laiguana, Recuenco y Madoz) no hay creadores ajenos al contexto occidental, ni aparece nadie vinculado al documentalismo social (sí, en cambio, a todos los demás temas enunciados: moda, publicidad, realidad paradójica), etc.

De hecho, por seguir con los ejemplos, ciertamente expresivos de la orientación del currículo, de sus presencias y de sus ausencias, el término documental aparece en una sola ocasión, dentro de la asignatura de primer curso, formando parte de un amplio paquete de contenidos que aborda géneros cinematográficos, géneros televisivos, cine de ficción y 
cine de animación. Ahí está la única referencia, que luego por supuesto no se desarrolla en criterios de evaluación 0 estándares de aprendizaje evaluables, pese a que en el preámbulo del Real Decreto se afirme la necesidad de que el alumnado sepa leer los productos audiovisuales para comprender su mensaje.

De este modo, los estamentos educativos de diversas comunidades autónomas, las subcomisiones de materia encargadas de elaborar los exámenes de la EvAU y, por supuesto, los propios docentes han buscado, en ocasiones de manera un tanto arriesgada, aunque muy elogiable desde nuestra perspectiva, estimular determinadas propuestas. En Valencia, por ejemplo, se ha introducido como sugerencia la posibilidad de trabajar únicamente sobre seis largometrajes, entre los cuales figura Te doy mis ojos (Icíar Bollaín, 2003), que por supuesto está en las antípodas de ser una comedia y que figura en la lista merced a una firme decisión de aprovechar la posibilidad de introducir contenidos transversales, como en este caso es el tratamiento de la violencia machista, para, además, lograr que una cineasta pueda colarse en la relación nominal que forma parte de los contenidos evaluables.

Hasta tal punto llaman poderosamente la atención determinadas especificaciones del currículo que, por no salirnos siquiera del ámbito de los nombres, se plantea el estudio de Max Linder o de Mack Sennett al tiempo que se desaprovecha la ocasión para trabajar con el alumnado a determinados creadores que mantuvieron una fértil trayectoria en distintos campos, al margen del específicamente cinematográfico: así, por ejemplo, los que como Alfred Hitchcock, Chicho Ibáñez Serrador o Pilar Miró desarrollaron también una notable actividad en el ámbito televisivo.

Por supuesto que este enjuiciamiento crítico no trata de sugerir nombres, ni de lamentar ausencias concretas, sino más bien de constatar que las decisiones adoptadas en el currículo y las exigencias específicas que demandan sus contenidos deberían instarnos a repensar colectivamente la materia de Cultura Audiovisual. Preguntarnos de nuevo el porqué y el para qué de estas dos asignaturas en los estudios de bachillerato, así como también el cómo puede hacerse, de manera viable, y qué márgenes de flexibilidad deben existir o ser permisibles. Definir si lo fundamental es la memorización, el análisis o la creatividad; lo tecnológico, lo fisiológico, lo económico, lo histórico o lo analítico.

\section{El currículo ante la EvAU}

La existencia de una prueba de evaluación para el acceso a la universidad del estudiantado de segundo de bachillerato delimita sustancialmente, en cualquier caso, el ambicioso magma de contenidos, criterios de evaluación y estándares de aprendizaje evaluables dentro de la materia de Cultura Audiovisual II, básicamente porque obliga a confrontar las amplias dimensiones, ambigüedades e indefiniciones del currículo con la realidad docente. Cualquier programación que quiera hacerse manteniendo todos los contenidos recogidos en la norma está condenada a saltar por los aires ante la tozuda realidad del día a día en las aulas, donde hay un número limitado de horas de clase y toda suerte de cuestiones adicionales por atender. En este sentido, si algo parece estar claro es que, al margen de que gusten más 0 menos su estructura y desarrollo, sus planteamientos conceptuales o sus orientaciones discursivas, el currículo actual de Cultura Audiovisual II resulta difíilmente viable en el marco de un curso, segundo de bachillerato, donde no hay suficiente tiempo como para abordar todo lo que plantea en su actual configuración y ello resulta evidente cuando se analizan los distintos posicionamientos adoptados por los estamentos educativos de cada comunidad autónoma y/o por las subcomisiones de materia nombradas al efecto de elaborar los exámenes de la EvAU.

Así, un primer eje de tensión en torno al currículo de Cultura Audiovisual II tiene que ver precisamente con lo que parece una necesidad de añadir, de cortar o de orientar los contenidos, criterios de evaluación y estándares de aprendizaje evaluables. Aquí encontramos de todo, si bien la primera de las opciones es precisamente la menos seguida: apenas cabe encontrarla en lugares como Canarias, donde su apuesta explícita por la introducción de enfoques transversales sugiere "plantear diversos temas, desde las realidades del mundo contemporáneo en sus 
dimensiones social, cultural o medioambiental, fomentando actitudes participativas y solidarias, orientadas al desarrollo y mejora de su entorno; hasta la educación física y el deporte o la seguridad vial"8 y y termina añadiendo: "En el desarrollo de estos temas transversales se prestará especial atención a los relativos a la violencia de género y a la no discriminación por razones de identidad y orientación sexual, religión o cultura, y a las personas con discapacidad"9.

Lo más habitual, sin embargo, es que los responsables educativos de las distintas comunidades autónomas y universidades, así como las subcomisiones de materia nombradas para elaborar los exámenes, propongan matizaciones notables sobre el currículo o juzguen directamente ciertos contenidos como eliminables. De nuevo Canarias puede ser un buen ejemplo, en una doble dirección: por un lado, al sintetizar los veintisiete criterios de evaluación que figuran en la norma legal publicada por el Boletín Oficial del Estado en apenas diez criterios (que, por supuesto, a veces engloban en su nueva redacción varios puntos de la normativa estatal); por otro lado, al delegar en las subcomisiones de materia la posibilidad de llegar a acuerdos con los docentes para definir ciertos contenidos como directamente prescindibles ${ }^{10}$. De este modo, por ejemplo, el cuarto criterio de evaluación recogido por el Gobierno de Canarias acoge, a su manera, todo el segundo bloque de la normativa estatal, denominado Características de la producción audiovisual y multimedia en los diferentes medios, que en origen tenía nada menos que cuatro criterios distintos de evaluación, y marca bien a las claras hasta el planteamiento incluso que debe seguirse:

Elaborar un proyecto colaborativo que sivva de base para realizar una exposición en clase sobre las características técnicas, expresivas y comunicativas de los procesos de producción, postproducción y efectos especiales de los diferentes medios de comunicación, con la finalidad de obtener una visión global de la evolución histórica de los medios de producción audiovisual, radiofónica y multimedia, y de apreciar la complejidad técnica de las producciones audiovisuales, multimedia y radiofónicas actuales".

${ }^{8} 0$, p. 110.

${ }^{9}$ Ibid.

${ }^{10}$ En el presente curso 2020-2021, ya en la primera reunión de la subcomisión de materia, celebrada el pasado 29 de octubre, quedó aprobada una Propuesta de secuencia, orden de impartición y temporalización de los bloques de aprendizaje que entre otras cuestiones recogía explícitamente que eran prescindibles el tercero de los contenidos asociados al primer bloque; el sexto y el séptimo vinculados al tercer bloque; y el noveno, adscrito al cuarto bloque. Es decir: los diez contenidos quedaban reducidos a seis con vistas a la EvAU, en clara manifestación de lo inabarcable que resulta esta materia en su configuración curricular. Ver Acta de la primera reunión de coordinación conjunta-Octubre 2020 en el siguiente enlace:

https://www.gobiernodecanarias.org/cmsweb/export/sites/educacion/web/bachillerato/_galerias/descargas/ebau-21/ac ta-primera-reunion-coordinacion-conjunta-ebau-cultura-audiovisual-octubre-2020.pdf (2020).

${ }^{11}$ Este criterio lleva una adenda explicativa, que dice lo siguiente: "Con este criterio se evaluará si el alumnado es capaz de elaborar y exponer un proyecto colaborativo en el que analice la evolución histórica de los medios técnicos al servicio de la producción, postproducción y efectos especiales de los medios audiovisuales (cine, televisión, vídeo y los sistemas multimedia) y de la radio, identificando los distintos equipos humanos que intervienen (realizadores, cámaras, técnicos de sonido, presentadores, guionistas, actores, maquilladores, técnicos de iluminación, decoradores, diseñadores gráficos, programadores informáticos...), comparando las características de las audiencias de esos medios y valorando la necesidad de la audio-descripción y la subtitulación de los productos audiovisuales y multimedia como medios para fomentar la igualdad efectiva de derechos y oportunidades a través del diseño universal. Se verificará también si relaciona esta evolución con las necesidades y características de los productos demandados por la sociedad. Se evaluará que, para todo ello, el alumnado es capaz de consultar diversas fuentes bibliográficas y digitales, utilizando las TIC como herramientas de investigación para buscar y seleccionar la información necesaria para documentarse y elaborar estos proyectos (interacción con sitios web, acceso digital a los medios...). Se valorará asimismo la capacidad del alumnado para planificar y participar activamente en un proceso de trabajo colaborativo, distribuyendo las tareas y realizando una coordinación eficaz del equipo, así como para valorar y respetar las aportaciones de los componentes y las componentes de este. Todo ello con la finalidad de apreciar la 
Si Canarias aboga por la sistematización, refundición y en algunos puntos omisión de los contenidos, criterios de evaluación o estándares de aprendizajes evaluables marcados por la normativa estatal, otras comunidades autónomas optan, en cambio, directamente por el recorte sustancial del currículo. Así, por ejemplo, Extremadura ha llegado en algunos momentos a eliminar estándares de aprendizaje, seleccionando como fundamental uno de ellos para cada bloque, con el objetivo de señalar el que debe ser esencialmente trabajado de manera más exhaustiva ${ }^{12}$, mientras que Castilla-La Mancha lleva planteando desde hace tiempo, por su parte, unos contenidos mínimos, que califica de consensuados, para su aplicación en la EvAU, suprimiendo directamente una cantidad enorme de los recogidos en el Real Decreto 1105/2014, de manera que, por ejemplo, los cuarenta y uno enunciados de contenidos que la normativa estatal exige para Cultura Audiovisual II quedan reducidos sólo a diez ${ }^{13}$.

Aunque estas decisiones puedan entenderse, lo cierto es que delatan la inviabilidad de asumir el currículo ni siquiera a veces en una cuarta parte de su extensión. Algo que, a todas luces, resulta difícilmente aceptable e invita a pensar en la necesidad de darle una vuelta a la normativa legal en vigor.

El segundo vértice de tensión en torno al currículo de Cultura Audiovisual II surge del siempre difícil encuentro entre ejercicio de memorización y capacidad analíica. Por mucho que en el preámbulo de la norma estatal se hable de que "esta materia pretende iniciar a los estudiantes en la fabricación de sus propias imágenes y productos audiovisuales, ya sean de naturaleza estática como la fotografía o dinámicas como el vídeo" y añada que "para esto es necesario que el alumnado esté en situación de analizar, relacionar y comprender los elementos que forman parte de la cultura audiovisual de nuestro tiempo"14, no es menos cierto que, probablemente a su pesar, los contenidos tienden a

complejidad técnica de las producciones audiovisuales, multimedia y radiofónicas actuales, y además desarrollar actitud de cooperación, iniciativa personal, autonomía y sentido crítico". Señalemos al respecto que la propia adaptación del currículo a la normativa autonómica del Gobierno de Canarias expone con rotundidad que "el modo de trabajar recomendado es el aprendizaje basado en problemas (ABP) o aprendizaje por proyectos". Véanse al respecto las páginas 28 y 6 , respectivamente, del currículo en el enlace

https://www.gobiernodecanarias.org/cmsweb/export/sites/educacion/web/_galerias/descargas/bachillerato/curriculo/n uevo_curriculo/nuevas_julio_2015/troncales/05_cultura_audiovisual.pdf(2016).

${ }^{12}$ Acta de reunión de coordinación de Cultura Audiovisual celebrada el 8 de febrero de 2017, disponible en

https://www.unex.es/organizacion/gobierno/vicerrectorados/vicealumn/archivos/ficheros/pau/coordinacion-ebau-

2016-17-1/cultura-audiovisual-ii/cultura_audiovisual_acta_08_02_17.pdf (2017).

${ }^{13}$ Directrices y orientaciones generales para la prueba de evaluación para el acceso a la universidad. Cultura Audiovisual II para la EVAU. Curso 2018-2019, disponible en

https://www.uclm.es/-/media/Files/A04-Gestion-Academica/PDFEstudiantes/PDFEvAU/CoordinacionMaterias1819/ cultura-audiovisual-WEB-2019.ashx?la=es (2019).

Describamos uno de los bloques de la asignatura para entenderlo con más claridad. En la normativa estatal el Bloque 3 plantea contenidos que abarcan cosas como los hitos de la televisión en el lenguaje audiovisual, la televisión en España, tipologías de programas para televisión y su realización, los grandes realizadores, la radio y la televisión interactivas, la radio y la televisión como servicios públicos, medios de comunicación de libre acceso, el uso responsable de la red o la libertad de expresión y los derechos individuales del espectador. Todos los cuales, y algunos que nos hemos dejado incluso en el tintero, saltan fuera por completo de los contenidos mínimos, que son en realidad los exigidos para la realización de la EvAU. Es más, se llega al extremo de que incluso dos de los tres únicos enunciados de contenidos que se han seleccionado del Boletín Oficial del Estado también son objeto de reformulación y poda, de manera que donde a redacción original del Real Decreto 1105/2014 dice "estudio de audiencias y programación; características de la obtención de los datos de audiencia; sistemas de elaboración, estadística de resultados y trascendencia en la producción audiovisual", el acuerdo de mínimos para Castilla-La Mancha lo deja en un escueto "estudio de audiencias y programación y trascendencia en la producción audiovisual".

${ }^{14}$ Real Decreto 1105/2014, de 26 de diciembre, por el que se establece el currículo básico de la Educación Secundaria Obligatoria y del Bachillerato. Boletín Oficial del Estado, 3 de enero de 2015, p. 226. 
estimular en ocasiones lo puramente memorístico, al incluir aspectos tales como las características técnicas del sonido, los principales compositores o realizadores, hitos históricos del cine o el estudio de audiencias y programación. De manera que muchos exámenes de la EvAU tienden inevitablemente a conformarse, en cierta medida, desde esta perspectiva, aunque en paralelo buscan sortearla de manera un tanto paradójica. El caso más llamativo en este sentido quizás sea el de Murcia, donde se opta directamente en la primera parte del examen (que supone el 40\% de la calificación) por una batería de preguntas tipo test y preguntas cortas, entre las cuales hay varias sobre la velocidad a la que se transmite el sonido, de qué depende el timbre de un sonido, cómo aumenta la calidad de una grabación digital en función del muestreo y del número de bits, etc.; pero, al mismo tiempo, con objeto de facilitarle las cosas a docentes y estudiantes está a disposición de todo el mundo, en abierto, una batería de preguntas posibles, muchas de ellas (las de tipo test) con sus respuestas. De esta manera, aunque el examen comprende en apariencia un enorme bagaje de conocimiento memorístico, lo cierto es que desde las aulas puede ser preparado a partir del repertorio de preguntas, con sus respuestas, que está disponible todos los años y que estos dos últimos cursos ni siquiera ha sufrido cambios.

De nuevo, aunque estas decisiones puedan entenderse vuelven a indicar que probablemente algo falla en el currículo.

El tercer elemento de tensión surge, como no podía ser menos, del hecho de que la materia de Cultura Audiovisual II establece, en su formulación normativa estatal, que su estructura persigue "dos caminos paralelos y complementarios", el primero de los cuales sería "el análisis de los productos" y el segundo "la creación por parte de alumnado de productos audiovisuales" ${ }^{\prime \prime}$. Es decir: análisis y creación parecen querer darse la mano dentro de la asignatura, pero cuando en realidad se estudian con detalle los criterios de evaluación y los estándares de aprendizaje evaluables es fácil vislumbrar cómo inevitablemente abunda el analizar frente al realizar. De hecho, en los estándares de aprendizaje la elaboración aparece tan sólo en cuatro ocasiones: realiza grabaciones de sonido con aparatos sencillos y valora los resultados obtenidos; realiza edición digital, convirtiendo piezas musicales de un sistema de sonido a otro (monoestéreo, PCM wav, aiff-mp3) y evalúa los resultados; construye piezas audiovisuales combinando imagen y sonido, integrando voz en off, piezas musicales y efectos en la narración visual; y elabora una pequeña producción audiovisual aplicando soluciones expresivas según el género y formato seleccionado. En cambio, la palabra analiza, al margen de otras posibles variantes (tipo reconoce, compara o explica) aparece en trece ocasiones, dejando claro de este modo que esos dos caminos paralelos y complementarios tienen, obviamente, distinta longitud y recorrido.

No obstante, algunas comunidades autónomas han optado para esta materia por metodologías activas basadas en el aprendizaje cooperativo e incluso algunas reflejan de manera explícita en sus orientaciones la necesidad de "saber ver para saber comprender y saber hacer para expresarse con la finalidad de comunicarse, producir, crear y conocer mejor la realidad y a uno mismo, para transformarla y transformarse" ${ }^{\prime \prime 1}$. De tal manera que al final tampoco existe acuerdo en torno a si debe privilegiarse en exclusiva el analizar (que es hacia lo que ha optado la mayoría) o puede y debe complementarse con el realizar.

Así, por ejemplo, en Castilla-La Mancha el segundo apartado del examen (que supone el 40\% de la calificación) recoge la posibilidad de optar por la elaboración del guion técnico "de una secuencia con un mínimo de 6 y un máximo de 12 planos donde se indicará el contenido del plano (narración de lo que ocurre en el plano), tipo de plano empleado, angulación y movimiento de cámara si lo hubiese y argumentación del porqué de cada decisión tomada", y "además se le añadirá la banda sonora de toda la secuencia (anotación de que existe diálogo si lo hubiera, efectos sonoros música

\footnotetext{
${ }^{15}$ Ibid., p. 227.

${ }^{16}$ Orden ECD/494/2016, de 26 de mayo, por la que se aprueba el currículo del Bachillerato y se autoriza su aplicación en los centros docentes de la Comunidad Autónoma de Aragón, publicada en el Boletín Oficial de Aragón del 3 de junio de 2016, p. 13575. Véase http://www.boa.aragon.es/cgi-bin/EBOA/BRSCGI?CMD=VEROBJ\&MLKOB=910897820707\&type=pdf (2016).
} 


\section{tapbiya $\mathbf{4 8}$}

extradiegética..., así como otros recursos que se consideren oportunos)"17. Otra opción del mismo examen se articula como un "ejercicio de creación de elementos sonoros", a partir de una serie de fotogramas, donde se pide a cada estudiante que lo elabore siguiendo estas pautas: "Visualiza la escena que se narra y crea una ambientación sonora para la misma, teniendo en cuenta los siguientes parámetros y aplicando los que creas oportunos: sonidos diegéticos y/o extradiegético, silencios, efectos sonoros, diálogos, cabalgados de sonido, sound-flow, música y planos sonoros ${ }^{18 \prime \prime}$.

También en Extremadura, por seguir con los ejemplos, se insta al estudiantado para que realice un storyboard de ocho viñetas a partir de un breve fragmento literario, usando "variedad de planos diferentes, angulación de cámara e iluminación", así como "el supuesto sonido adecuado a cada viñeta", o por el contrario elabore "un guion original e inédito" ${ }^{\prime 19}$ a partir de un conjunto de fotogramas predeterminado, y añadiéndole referencias al audio correspondiente, sin por ello eliminar del todo la posibilidad de, en vez de realizar, pasarse al ámbito del analizar (en este caso concreto, los fotogramas de una película mediante ítems predeterminados como tipo de plano, angulación, movimiento de cámara o iluminación).

No aspiramos a ser exhaustivos en el abordaje de las distintas variantes que el panorama nacional sobre los repertorios de exámenes de la EvAU en Cultura Audiovisual permitiría estudiar. En realidad, lo que se pretende señalar es que, tanto la literalidad del currículo como sus mecanismos de adaptación a la esfera docente delatan algunos hechos: pasados varios años desde su aprobación, ni parece haber quedado mínimamente claro qué es lo que se pretendía conseguir (análisis de imágenes, elaboración de materiales audiovisuales, ejercicios memorísticos...) 0 en qué grado cada cosa; ni cómo se pretendía que todo eso pudiera llevarse a cabo desde los centros de bachillerato y, por supuesto, a través de sus docentes; ni cuál era el margen de flexibilidad existente 0 al menos permisible, tanto para el profesorado como para las distintas subcomisiones de materia encargadas de la elaboración de los exámenes de la EvAU. Tampoco parece estar claro cómo afrontar el propio ejercicio de acceso a la universidad desde criterios relativamente homogéneos, como parecería exigir una prueba de alcance nacional que habilita para cursar determinados estudios en cualquier parte del Estado.

Desde nuestra perspectiva, las interpretaciones están siendo tan dispares como en ocasiones opuestas entre sí, y quizás haya llegado el momento de repensar todo el modelo desde la misma base: el texto normativo.

\footnotetext{
${ }^{17}$ Véase, por ejemplo, el examen de la convocatoria de junio del curso 2019-2020, disponible en https://www.uclm.es/perfiles/preuniversitario/acceso/evau/-/media/EB8EC62A059D493F98D6C811F82B0BF4.ashx (2020)

${ }^{18}$ Ibid.

${ }^{19}$ Véase el examen de la convocatoria de junio del curso 2019-2020, disponible en https://www.unex.es/organizacion/gobierno/vicerrectorados/vicealumn/archivos/ficheros/pau/coordinacion-ebau-201 9-2020/cultura-audiovisual/cultura_audiovisual_examen 2020.pdf (2020).
} 


\section{tarbiya $\mathbf{4 8}$}

\section{Normativa citada}

Acta de reunión de coordinación de Cultura Audiovisual celebrada el 8 de febrero de 2017.

https://www.unex.es/organizacion/gobierno/vicerrectorados/vicealumn/archivos/ficheros/pau/coordinacion-ebau-2016-17-1 /cultura-audiovisual-ii/cultura_audiovisual_acta_08_02_17.pdf

Acta de la primera reunión de coordinación conjunta, octubre de 2020. Gobierno de Canarias.

https://www.gobiernodecanarias.org/cmsweb/export/sites/educacion/web/bachillerato/_galerias/descargas/ebau-21/acta-pr imera-reunion-coordinacion-conjunta-ebau-cultura-audiovisual-octubre-2020.pdf

Decreto 83/2016, de 4 de julio, por el que se establece el currículo básico de la Educación Secundaria Obligatoria y el Bachillerato en la Comunidad Autónoma de Canarias.

http://www.gobiernodecanarias.org/boc/2016/136/001.html

Directrices y orientaciones generales para la prueba de evaluación para el acceso a la universidad. Cultura Audiovisual II para la EVAU. Curso 2018-2019.

https://www.udlm.es/-/media/Files/A04-Gestion-Academica/PDFEstudiantes/PDFEvAU/CoordinacionMaterias1819/cultura-au diovisual-WEB-2019.ashx!la=es

Orden ECD/494/2016, de 26 de mayo, por la que se aprueba el currículo del Bachillerato y se autoriza su aplicación en los centros docentes de la Comunidad Autónoma de Aragón.

http://www.boa.aragon.es/cgi-bin/EBOA/BRSCGI?CMD=VEROBJ\&MLKOB=910897820707\&type=pdf

Real Decreto 1105/2014, de 26 de diciembre, por el que se establece el currículo básico de la Educación Secundaria Obligatoria y el Bachillerato.

https://www.boe.es/boe/dias/2015/01/03/pdfs/BOE-A-2015-37.pdf 


\section{Bibliografía}

Arroyo Almaraz, I. (2009). Cultura audiovisual. Madrid: Ediciones del Laberinto.

Bazalgette, C. (1991). Los medios audiovisuales en la educación primaria. Madrid: Morata.

CASTILLO POMEDA, J. M. (2013). La composición de la imagen. Madrid: Paraninfo.

CASTILLO POMEDA, J. M. (2017). Cultura audiovisual I. $1^{\circ}$ Bachillerato LOMCE. Madrid: Paraninfo.

CASTlLLo PomedA, J. M. (2017). Cultura audiovisual II. $2^{\circ}$ Bachillerato LOMCE. Madrid: Paraninfo.

CAstillo POMEDA, J. M. (2002). Elementos del lenguaje audiovisual en televisión. Madrid: Instituto Oficial de Radio y Televisión.

Díez PuerTAS, E. (2014). Narrativa fílmica. Escribir la pantalla, pensar la imagen. Madrid: Fundamentos.

Fernández Diez, F. y Martínez Abadía, J. (1999). Manual básico de lenguaje y narrativa audiovisual. Barcelona: Paidós.

Gómez TARín, F. J. y MARzal Felicl, J. (eds.). (2015). Diccionario de conceptos y términos audiovisuales. Herramientas para el análisis filmico. Madrid: Cátedra.

GoRDILLo ÁlvaREZ, I. (2009). Manual de narrativa televisiva. Madrid: Síntesis.

GuARINOS Galán, V. (2009). Manual de narrativa radiofónica. Madrid: Síntesis.

Manovich, L. (2005). El lenguaje de los nuevos medios de comunicación. Barcelona: Paidós.

MarTínez Abadía, J. (1988). Introducción a la tecnología audiovisual: televisión, vídeo, radio. Barcelona: Paidós.

Martínez García, M. Á. y Gómez AgullaR, A. (2015). La imagen cinematográfica: manual de análisis aplicado. Madrid: Síntesis.

MILLERSON, G. (2001). Realización y producción en televisión. Madrid: Instituto Oficial de Radio y Televisión.

RODERO ANTÓN, E. y SOENGAS LÓPEZ, X. (2010). Ficción radiofónica. Madrid: Instituto Oficial de Radio y Televisión.

Rodero Antón, E. (2005). Producción radiofónica. Madrid: Cátedra.

Villafañe Gallego, J. y Mínguez ArRanz, N. (2002). Principios de teoría general de la imagen. Madrid: Pirámide.

ZÚÑIGA RódenAS, J. (2009). Cultura audiovisual. Guipúzcoa: Escuela de Cine y Vídeo de Andoain. 


\section{tgphiyg $\mathbf{4 8}$}

\section{Resumen.}

Las enseñanzas de cultura audiovisual, reguladas de acuerdo al Real Decreto 1105/2014, han estado sujetas desde su misma plasmación normativa a un intenso cuestionamiento en el ámbito docente. Pasado un tiempo prudencial desde su implantación, este artículo establece unas primeras revisiones críticas de los contenidos, criterios de evaluación y estándares de aprendizaje evaluables que presentan las dos asignaturas (Cultura Audiovisual I y Cultura Audiovisual II), con el objeto de efectuar una llamada a la reflexión colectiva sobre el devenir actual de estas enseñanzas y su innegable potencial futuro.

Palabras clave. Cultura Audiovisual; Bachillerato; Currículo; Selección y secuenciación de contenidos.

\section{Abstract.}

Audiovisual culture education at High School level, regulated in the Real Decreto 1105/2014, has been brough into question by teaching community since its just implementation. Having passed a reasonable time from then on, this article aims to cast a critical review on curriculum contents, assessment criteria and evaluable learning standards stablished for two Baccalaureate subjects (Audiovisual Culture I and Audiovisual Culture II) inviting to a collective reflection on present actualization of that education realm and its unquestionable potential in the future.

Key-words. Audiovisual Culture; Baccalaureate; Curriculum; Selection and secuencing of contents.

Luis Fernández Colorado

Universidad Autónoma de Madrid

luis.colorado@uam.es 